\title{
Toxoplasma Gondii Infection and a History of Surgery: A Case Control Seroprevalence Study
}

\author{
Cosme Alvarado-Esquivel ${ }^{*}$, Luis Francisco Sánchez-Anguiano², Jesús Hernández-Tinoco², \\ Agar Ramos-Nevarez ${ }^{3}$, Sergio Estrada-Martínez ${ }^{2}$, Sandra Margarita Cerrillo-Soto ${ }^{3}$, \\ Miriam Alejandra Mijarez-Hernández ${ }^{4}$, Carlos Alberto Guido-Arreola ${ }^{3}$, Alma Rosa Pérez-Álamos ${ }^{2}$, \\ Isabel Beristain-Garcia ${ }^{4}$ and Elizabeth Rábago-Sánchez ${ }^{5}$ \\ ${ }^{1}$ Biomedical Research Laboratory, Faculty of Medicine and Nutrition, Juárez University of Durango State, \\ Avenida Universidad S/N, 34000 Durango, Mexico \\ ${ }^{2}$ Institute for Scientific Research "Dr. Roberto Rivera-Damm”, Juárez University of Durango State, \\ Avenida Universidad S/N, 34000 Durango, Mexico \\ ${ }^{3}$ Clínica de Medicina Familiar, Instituto de Seguridad y Servicios Sociales de los Trabajadores del Estado, \\ Predio Canoas S/N, 34079 Durango, Mexico \\ ${ }^{4}$ Facultad de Enfermería y Obstetricia, Juárez University of Durango State, Cuauhtémoc 223 norte, 34000 Durango, Mexico \\ ${ }^{5}$ Hospital General, Secretaría de Salud, Avenida 5 de febrero y Norman Fuentes, 34000 Durango, Mexico
}

Received: 09 August 2018; accepted: 14 October 2018

\begin{abstract}
We determined the association between having a history of surgery and the seroreactivity to $T$. gondii. An age- and gender-matched case-control study of 391 subjects with a history of surgery and 391 subjects without this history was performed. Sera of subjects were analyzed for detection of anti-T. gondii immunoglobulin $\mathrm{G}(\operatorname{IgG})$ and $\mathrm{M}$ $(\operatorname{IgM})$ antibodies using enzyme-linked immunoassays. Anti-T. gondii $\operatorname{IgG}$ antibodies were found in $25(6.4 \%)$ of the 391 cases and in $21(5.4 \%)$ of the 391 controls (odds ratio [OR] $=1.29$; 95\% confidence interval [CI]: $0.66-$ $2.18 ; P=0.54)$. The frequency of cases with high IgG antibody levels $(10 / 25: 40.0 \%)$ was equal to that found in controls $(8 / 21: 38.1 \%)(\mathrm{OR}=1.08 ; 95 \% \mathrm{CI}: 0.32-3.56 ; P=0.89)$. Of the 25 anti-T. gondii IgG antibody seropositive cases, $5(16.0 \%)$ were also positive for anti-T. gondii IgM antibodies. Meanwhile, of the 21 anti-T. gondii $\operatorname{IgG}$ antibody seropositive controls, $4(19.0 \%)$ were also positive for anti-T. gondii IgM antibodies (OR $=0.81 ; 95 \%$ CI: $0.17-3.72 ; P=0.80$ ). Logistic regression showed that only the variable "hysterectomy" was associated with $T$. gondii seropositivity $(\mathrm{OR}=4.6$; $95 \% \mathrm{CI}: 1.6-13.4 ; P=0.005)$. Results suggest that having a history of surgery is not an important risk factor for infection with $T$. gondii. However, the link between T. gondii infection and hysterectomy should be further investigated.
\end{abstract}

Keywords: Toxoplasma gondii, infection, seroprevalence, surgery, case-control study, epidemiology, Mexico

\section{Introduction}

Toxoplasma gondii (T. gondii) is an obligate intracellular protozoan parasite that causes infections in warm blooded animals including humans [1]. Infections with $T$. gondii in man are commonly asymptomatic or cause mild symptoms that are self-limited [2]. Symptoms of T. gondii infection include malaise, lethargy, and lymphadenitis [3]. Immunocompromised patients may experience more severe clinical manifestations of toxoplasmosis including chorioretinitis, splenomegaly, encephalitis, pneumonitis, and multisystem organ failure [3, 4]. Primary infection with $T$. gondii during pregnancy may have serious consequences for the fetus, i.e., miscarriage, central nervous system involvement, or eye disease [5]. Infection with $T$. gondii may be acquired by ingestion of tissue cysts or tachyzoites contained in meat, or ingestion of environmental sporulated oocysts in contaminated food or water [6]. In addition, infection with $T$. gondii may occur by blood transfusion [7] and organ transplantation $[8,9]$.

Very little is known about the association between $T$. gondii infection and having a history of surgery. Patients undergoing

\footnotetext{
*Author for correspondence: Laboratorio de Investigación Biomédica. Facultad de Medicina y Nutrición. Avenida Universidad S/N. 34000 Durango, Dgo, México; E-mail: alvaradocosme@yahoo.com; Tel/Fax: 0052-618-8130527.
}

surgery may be at risk for infection with $T$. gondii if they receive blood transfusions or organ transplants from $T$. gondiiinfected donors. However, the magnitude of this association is largely unknown. The presence of tissue cysts in organs and tachyzoites in blood from $T$. gondii-infected donors are involved in the parasite transmission to seronegative recipients. It is unclear whether $T$. gondii can be transmitted by surgical procedures other than organ transplant. It is also unknown whether the use of contaminated materials during surgery might be involved in the transmission of $T$. gondii infection. Surgery has been linked to infection with $T$. gondii in several studies. A positive association between infection with $T$. gondii and a history of surgery was found in psychiatric patients [10], women with a history of stillbirths [11], and people applying for medical certificates [12] in Durango City, Mexico. It is unclear whether the association found in these population groups was influenced by any factor. There is a need to confirm or challenge such association using a case-control study design. To the best of our knowledge, no previous casecontrol study about the association between infection with T. gondii and a history of surgery has been reported. Therefore, this study aimed to determine the association between seropositivity to $T$. gondii and a history of surgery of people in Durango City, Mexico.

This is an open-access article distributed under the terms of the Creative Commons Attribution-NonCommercial 4.0 International License (https://creativecommons.org/licenses/by-nc/4.0/), which permits unrestricted use, distribution, and reproduction in any medium for non-commercial purposes, provided the original author and source are credited, a link to the CC License is provided, and changes - if any - are indicated. 


\section{Materials and Methods}

Study Design. We performed an age- and gender-matched case-control seroprevalence study of 391 subjects with (cases) and 391 subjects without (controls) a history of surgery. This study was performed from January 2015 to May 2018 in Durango City, Mexico.

Subjects Studied. Subjects with a history of surgery were enrolled in 4 public health care centers in Durango City, Mexico: the family care center of the Institute of Security and Social Services of State Workers, the Health Care Center No. 2 and the psychiatric hospital "Dr. Miguel Vallebueno" of the Secretary of Health, and the municipal Clinic of Sanitary Inspection. Selection of participants was carried out by using a simple random sampling. Inclusion criteria for the cases were as follows: a) having a history of surgery, b) 13 years and older, c) any gender, and d) who voluntarily participate in the study. Cases were $13-78($ mean $=36.56 \pm 11.3)$ years old and included 45 males (11.5\%) and $346(88.5 \%)$ females. Number of surgeries, type of surgery, organ or tissue operated, and surgery specialties were recorded from each case. Inclusion criteria for the controls were: a) no having a history of surgery, b) 13 years and older, c) any gender, and d) who voluntarily participate in the study. Controls were subjects randomly selected from the general population in Durango City and were matched with cases by gender, age, birthplace (Durango State, Mexico), and urban residence (Durango City). Controls included 45 males (11.5\%) and 346 females $(88.5 \%)$ aged $13-78($ mean $=36.56 \pm 11.3)$ years old, and their age was not different from that in cases $(P=1.00)$.

Detection of Anti-T. Gondii Immunoglobulin G (IgG) and $M$ (IgM) Antibodies. A serum sample from each case and control was examined for the presence of anti- $T$. gondii IgG and IgM antibodies. Anti-T. gondii IgG antibodies was detected with the commercially available enzyme immunoassay kit "Toxoplasma IgG" (Diagnostic Automation Inc., Woodland Hills, CA, USA). This test allowed the quantification of anti- $T$. gondii $\mathrm{IgG}$ antibody in International Units (IU) $/ \mathrm{mL}$. A cutoff $\geq 8 \mathrm{IU} / \mathrm{mL}$ was used for seropositivity as indicated in the kit's insert. Serum samples positive for anti$T$. gondii $\operatorname{IgG}$ antibodies were further analyzed for anti- $T$. gondii IgM antibodies by the commercially available enzyme immunoassay "Toxoplasma IgM" kit (Diagnostic Automation Inc.), following the instructions of the manufacturer.

Statistical Analysis. The statistical analysis of data was performed with the software Epi Info version 7 (Centers for Disease Control and Prevention: http://wwwn.cdc.gov/epiinfo/) and SPSS version 15.0 (SPSS Inc. Chicago, Illinois). We calculated the sample size using the following data: a $95 \%$ confidence level, a power of $80 \%$, a $1: 1$ proportion of cases and controls, a reference seroprevalence of $6.1 \%$ [13] as the expected frequency of exposure in controls, and an odds ratio (OR) of 2.1. The result of the sample size calculation was 370 cases and 370 controls. The student's $t$ test was used to compare the age of cases and controls. We determined the association between $T$. gondii seropositivity and surgery data with the Pearson's chi-square test. We determined the association between $T$. gondii seropositivity and surgery variables with $P$ values $\leq 0.20$ obtained in the bivariate analysis using logistic regression analysis with the Enter method. OR and 95\% confidence intervals (CI) were calculated. A $P$ value less than 0.05 was considered as statistically significant.

Ethics Aspects. This project was approved by the Ethics Committee of the General Hospital of the Secretary of Health in Durango City, Mexico. All participants received information about the purpose and procedures of this study,
Table 1. Comparison of seropositivity rate to $T$. gondii according to sex and age between cases and controls

\begin{tabular}{|c|c|c|c|c|c|c|c|}
\hline \multirow[t]{3}{*}{ Characteristic } & \multicolumn{3}{|c|}{ Cases } & \multicolumn{3}{|c|}{ Controls } & \multirow[t]{3}{*}{$P$ value } \\
\hline & \multirow[t]{2}{*}{$\begin{array}{l}\text { No. } \\
\text { tested }\end{array}$} & \multicolumn{2}{|c|}{$\begin{array}{l}\text { Seroprevalence } \\
\text { of T. gondii } \\
\text { infection }\end{array}$} & \multirow[t]{2}{*}{$\begin{array}{l}\text { No. } \\
\text { tested }\end{array}$} & \multicolumn{2}{|c|}{$\begin{array}{l}\text { Seroprevalence } \\
\text { of } T \text {. gondii } \\
\text { infection }\end{array}$} & \\
\hline & & No. & $\%$ & & No. & $\%$ & \\
\hline \multicolumn{8}{|l|}{$\overline{\text { Sex }}$} \\
\hline Male & 45 & 2 & 4.4 & 45 & 2 & 4.4 & 1.0 \\
\hline Female & 346 & 23 & 6.6 & 346 & 19 & 5.5 & 0.52 \\
\hline \multicolumn{8}{|c|}{ Age (years old) } \\
\hline 30 or less & 132 & 11 & 8.3 & 132 & 6 & 4.5 & 0.21 \\
\hline $31-50$ & 203 & 11 & 5.4 & 203 & 12 & 5.9 & 0.83 \\
\hline$>50$ & 56 & 3 & 5.4 & 56 & 3 & 5.4 & 1.0 \\
\hline
\end{tabular}

and a written informed consent to participate in the study was obtained from each of them.

\section{Results}

Anti-T. gondii $\operatorname{IgG}$ antibodies were found in $25(6.4 \%)$ of the 391 cases and in $21(5.4 \%)$ of the 391 controls (OR = 1.29; 95\% CI: $0.66-2.18 ; P=0.54)$. Stratification by age and gender showed no difference $(P>0.05)$ in the seroprevalence of $T$. gondii infection between cases and controls (Table 1). Of the 25 anti-T. gondii IgG positive cases, $10(40.0 \%)$ had antiT. gondii IgG antibody levels higher than $150 \mathrm{IU} / \mathrm{mL}, 3$ (12.0\%) between $100 \mathrm{IU} / \mathrm{mL}$ and $150 \mathrm{IU} / \mathrm{mL}$, and $12(48.0 \%)$ between 8 to $99 \mathrm{IU} / \mathrm{mL}$. In contrast, of the 21 anti- $T$. gondii IgG positive controls, 8 (38.1\%) had anti-T. gondii IgG antibody levels higher than $150 \mathrm{IU} / \mathrm{mL}, 2$ (9.5\%) between $100 \mathrm{IU} / \mathrm{mL}$ and $150 \mathrm{IU} / \mathrm{mL}$ and $11(52.4 \%)$ between 8 to $99 \mathrm{IU} / \mathrm{mL}$. The frequency of subjects with high $\mathrm{IgG}$ antibody levels in cases was equal to that found in controls $(\mathrm{OR}=1.08$; 95\% CI: $0.32-3.56 ; P=0.89$ ).

Of the 25 anti- $T$. gondii IgG antibody seropositive cases, 5 (16.0\%) were also positive for anti-T. gondii IgM antibodies. Meanwhile, of the 21 anti- $T$. gondii IgG antibody seropositive controls, $4(19.0 \%)$ were also positive for anti-T. gondii IgM antibodies. No difference in the rate of IgM seropositivity

Table 2. Correlation of T. gondii seroprevalence and types of surgery

\begin{tabular}{|c|c|c|c|c|c|c|c|}
\hline \multirow{3}{*}{$\begin{array}{l}\text { Type of } \\
\text { surgery } \\
\text { in cases }\end{array}$} & \multicolumn{3}{|c|}{ Cases } & \multicolumn{3}{|c|}{ Controls } & \multirow{3}{*}{$\begin{array}{l}\text { Cases vs } \\
\text { controls* } \\
P \text { value }\end{array}$} \\
\hline & \multirow[t]{2}{*}{$\begin{array}{l}\text { No. } \\
\text { tested }\end{array}$} & \multicolumn{2}{|c|}{$\begin{array}{c}\text { Prevalence } \\
\text { of } T \text {. gondii } \\
\text { infection } \\
\end{array}$} & \multirow[t]{2}{*}{$\begin{array}{l}\text { No. } \\
\text { tested }\end{array}$} & \multicolumn{2}{|c|}{$\begin{array}{c}\text { Prevalence } \\
\text { of } T \text {. gondii } \\
\text { infection }\end{array}$} & \\
\hline & & No. & $\%$ & & No. & $\%$ & \\
\hline Appendectomy & 44 & 3 & 6.8 & 44 & 2 & 4.5 & 1.00 \\
\hline Braquioplasty & 4 & 1 & 25.0 & 4 & 0 & 0.0 & 1.00 \\
\hline Cesarean section & 167 & 9 & 5.4 & 167 & 10 & 6.0 & 0.81 \\
\hline Cholecystectomy & 41 & 4 & 9.8 & 41 & 1 & 2.4 & 0.35 \\
\hline Cyst removal & 9 & 0 & 0.0 & 9 & 1 & 11.1 & 1.00 \\
\hline Fat removal & 3 & 0 & 0.0 & 3 & 0 & 0.0 & - \\
\hline Hernia repair & 15 & 2 & 13.3 & 15 & 1 & 6.7 & 1.00 \\
\hline Hysterectomy & 22 & 5 & 22.7 & 22 & 1 & 4.5 & 0.18 \\
\hline Knee arthroscopy & 11 & 1 & 14.3 & 11 & 0 & 0.0 & 1.00 \\
\hline Mammoplasty & 4 & 1 & 25.0 & 4 & 0 & 0.0 & 1.00 \\
\hline Maxillofacial surgery & 5 & 0 & 0.0 & 5 & 0 & 0.0 & - \\
\hline Nephrectomy & 5 & 0 & 0.0 & 5 & 0 & 0.0 & - \\
\hline Osteoplasty & 17 & 1 & 5.9 & 17 & 0 & 0.0 & 1.00 \\
\hline Periodontal surgery & 69 & 4 & 5.8 & 69 & 3 & 4.3 & 1.00 \\
\hline Phlebectomy & 3 & 0 & 0.0 & 3 & 0 & 0.0 & - \\
\hline Refractive eye surgery & 11 & 1 & 9.1 & 11 & 1 & 9.1 & 1.00 \\
\hline Rhinoplasty & 4 & 0 & 0.0 & 4 & 0 & 0.0 & - \\
\hline Salpingectomy & 57 & 0 & 0.0 & 57 & 5 & 8.8 & 0.05 \\
\hline Salpingo-oophorectomy & 4 & 1 & 25.0 & 4 & 1 & 25.0 & 1.00 \\
\hline Tissue removal & 3 & 0 & 0.0 & 3 & 0 & 0.0 & - \\
\hline Tonsillectomy & 16 & 0 & 0.0 & 16 & 0 & 0.0 & - \\
\hline Uterine curettage & 16 & 0 & 0.0 & 16 & 0 & 0.0 & - \\
\hline
\end{tabular}


Table 3. Correlation of $T$. gondii seroprevalence and organ, tissue or anatomical region of surgery

\begin{tabular}{|c|c|c|c|c|c|c|c|}
\hline \multirow{3}{*}{$\begin{array}{l}\text { Organ, tissue or } \\
\text { region operated } \\
\text { in cases }\end{array}$} & \multicolumn{3}{|c|}{ Cases } & \multicolumn{3}{|c|}{ Controls } & \multirow{3}{*}{$\begin{array}{l}\text { Cases vs } \\
\text { controls* } \\
P \text { value }\end{array}$} \\
\hline & \multirow[t]{2}{*}{$\begin{array}{l}\text { No. } \\
\text { tested }\end{array}$} & \multicolumn{2}{|c|}{$\begin{array}{c}\text { Prevalence } \\
\text { of } T \text {. gondii } \\
\text { infection }\end{array}$} & \multirow[t]{2}{*}{$\begin{array}{l}\text { No. } \\
\text { tested }\end{array}$} & \multicolumn{2}{|c|}{$\begin{array}{c}\text { Prevalence } \\
\text { of } T . \text { gondii } \\
\text { infection }\end{array}$} & \\
\hline & & No. & $\%$ & & No. & $\%$ & \\
\hline Abdominal cavity & 22 & 2 & 9.1 & 22 & 1 & 4.5 & 1.00 \\
\hline Appendix & 43 & 3 & 7.0 & 43 & 2 & 4.7 & 1.00 \\
\hline Arm & 4 & 1 & 25.0 & 4 & 0 & 0.0 & 1.00 \\
\hline Blood vessels & 3 & 0 & 0.0 & 3 & 0 & 0.0 & - \\
\hline Bones & 16 & 1 & 6.3 & 16 & 0 & 0.0 & 1.00 \\
\hline Breast & 5 & 1 & 20.0 & 5 & 0 & 0.0 & 1.00 \\
\hline Eyes & 6 & 0 & 0.0 & 6 & 1 & 16.7 & 1.00 \\
\hline Fallopian tubes & 58 & 0 & 0.0 & 58 & 5 & 8.6 & 0.05 \\
\hline Fingers & 3 & 0 & 0.0 & 3 & 0 & 0.0 & - \\
\hline Gallbladder & 41 & 4 & 9.8 & 41 & 1 & 2.4 & 0.35 \\
\hline Intestine & 3 & 0 & 0.0 & 3 & 0 & 0.0 & - \\
\hline Joint & 9 & 1 & 11.1 & 9 & 0 & 0.0 & 1.00 \\
\hline Kidney & 7 & 0 & 0.0 & 7 & 0 & 0.0 & - \\
\hline Maxillary & 5 & 0 & 0.0 & 5 & 0 & 0.0 & - \\
\hline Nose & 5 & 0 & 0.0 & 5 & 0 & 0.0 & - \\
\hline Ovary & 5 & 1 & 20.0 & 5 & 1 & 20.0 & 1.00 \\
\hline Retina & 6 & 1 & 16.7 & 6 & 0 & 0.0 & 1.00 \\
\hline Teeth & 70 & 4 & 5.7 & 70 & 3 & 4.3 & 1.00 \\
\hline Tonsils & 16 & 0 & 0.0 & 16 & 0 & 0.0 & - \\
\hline Uterus & 188 & 13 & 6.9 & 188 & 11 & 5.9 & 0.67 \\
\hline
\end{tabular}

between cases and controls was found ( $\mathrm{OR}=0.81 ; 95 \% \mathrm{CI}$ : $0.17-3.72 ; P=0.80)$.

Concerning the number of surgeries, cases had had between 1 to 6 surgeries. The seroprevalence of $T$. gondii infection did not vary $(P=0.75)$ with the number of surgeries: $6.0 \%$ in subjects with one surgery, $8.1 \%$ in those with 2 surgeries, and $5.6 \%$ in those with 3 or more surgeries.

Bivariate analysis showed no association between $T$. gondii seropositivity and the type of surgery (Table 2), or organ, tissue, or region operated (Table 3 ). Only the variables "hysterectomy", "salpingectomy", and "fallopian tubes" showed a $P$ value of $\leq 0.20$. Meanwhile, bivariate analysis of the $T$. gondii seropositivity rate and surgical specialties showed two variables with a $P$ value of $\leq 0.20$ : general surgery and orthopedic surgery (Table 4).

Further analysis by logistic regression of variables that obtained a $P$ value of $\leq 0.20$ in the bivariate analysis (hysterectomy, general surgery, and orthopedic surgery) showed that only the variable "hysterectomy" was associated with $T$. gondii seropositivity $(\mathrm{OR}=4.6$; 95\% CI: $1.6-13.4 ; P=0.005)$. The variables "salpingectomy" and "fallopian tubes" were not included in the regression analysis, because no seropositive cases with these characteristics were found (zero values in the cells).

Discussion. The epidemiological link between infection with $T$. gondii and surgical procedures has been scantily studied. We are not aware of any age- and gender-matched case control study on the association between $T$. gondii infection and a history of surgery. In this study, we not only aimed to determine this association using an age- and gendermatching but also took matching by birthplace and residency into consideration. This strategy provided a more stringent study design. In several epidemiological studies on $T$. gondii infection in Durango, Mexico, we have observed that people born in Mexican states other than Durango had a higher seroprevalence of $T$. gondii infection than those born in Durango State [12-14]. In addition, people living in rural Durango [15] had a higher seroprevalence of $T$. gondii infection than those residing in the urban Durango City [13]. We found similar frequencies of anti-T. gondii IgG and IgM antibodies in cases to those found in controls. In addition,
Table 4. Correlation of $T$. gondii seroprevalence and surgical specialties

\begin{tabular}{|c|c|c|c|c|c|c|c|}
\hline \multirow{3}{*}{$\begin{array}{l}\text { Specialty that } \\
\text { attended cases }\end{array}$} & \multicolumn{3}{|c|}{ Cases } & \multicolumn{3}{|c|}{ Controls } & \multirow{3}{*}{$\begin{array}{l}\begin{array}{l}\text { Cases vs } \\
\text { control }^{a}\end{array} \\
P \text { value }\end{array}$} \\
\hline & \multirow[t]{2}{*}{$\begin{array}{l}\text { No. } \\
\text { tested }\end{array}$} & \multicolumn{2}{|c|}{$\begin{array}{c}\text { Prevalence } \\
\text { of } T \text {. gondii } \\
\text { infection }\end{array}$} & \multirow[t]{2}{*}{$\begin{array}{l}\text { No. } \\
\text { tested }\end{array}$} & \multicolumn{2}{|c|}{$\begin{array}{l}\text { Prevalence } \\
\text { of } T \text {. gondii } \\
\text { infection }\end{array}$} & \\
\hline & & No. & $\%$ & & No. & $\%$ & \\
\hline Angiology & 4 & 0 & 0.0 & 4 & 0 & 0.0 & - \\
\hline Gener & 105 & 9 & 8.6 & 105 & 4 & 3.8 & 0.15 \\
\hline Plastic surgery & 8 & 1 & 12.5 & 8 & 1 & 12.5 & 1.00 \\
\hline $\begin{array}{l}\text { Obstetrics and } \\
\text { gynecology }\end{array}$ & 236 & 14 & 5.9 & 236 & 16 & 6.8 & 0.70 \\
\hline Thoracic surgery & 4 & 0 & 0.0 & 4 & 0 & 0.0 & - \\
\hline Odont & 73 & 4 & 5.5 & 73 & 3 & 4.1 & 1.00 \\
\hline Ophthe & 12 & 1 & 8.3 & 12 & 1 & 8 & 1.00 \\
\hline Orthopedic surgery & 35 & 4 & 11.4 & 35 & 0 & 0.0 & 0.11 \\
\hline Otorhinolaryngology & 18 & 0 & 0.0 & 18 & 0 & 0.0 & - \\
\hline Urology & 11 & 0 & 0.0 & 11 & 0 & 0 & - \\
\hline
\end{tabular}

stratification by age and gender groups showed no difference in the $\operatorname{IgG}$ and $\operatorname{IgM}$ seroprevalence between cases and controls. Similarly, the frequency of high $(>150 \mathrm{IU} / \mathrm{mL})$ anti- $T$. gondii antibody levels in cases was equal to that found in controls. The results thus suggest that there was no association between seropositivity to $T$. gondii and a history of surgery in the people studied. This finding was unexpected because several studies in our region have found an association between seropositivity to T. gondii and a history of surgery. In Durango City, we found a positive association between $T$. gondii infection and a history of surgery in psychiatric patients [10], women with a history of stillbirths [11], and people applying for medical certificates [12]. Similarly, T. gondii infection was associated with a history of hernia repair [16]. In addition, in a study of Yoremes, an ethnic group in the northwestern Mexican State of Sonora, we found that $T$. gondii exposure was associated with a history of cesarean sections in the women surveyed [17]. The reason for the association between seropositivity to $T$. gondii and a history of surgery was found in previous studies but not in the present study could be explained by the difference in the aims, number of cases, and research methods among the studies. Firstly, in the present study the main aim was to determine the association between $T$. gondii infection and a history of surgery, whereas this association was assessed as a secondary aim in the studies in psychiatric patients [10], women with a history of stillbirths [11], and people applying for medical certificates [12]. This fact is important because control of variables (age, gender, etc.) is focused predominantly in reaching the main aim rather than secondary aims. Secondly, in the present study, we studied 391 cases, whereas the number of cases was low in previous studies, i.e., 55 cases were analyzed in the study of hernia repair [16], 95 in women with a history of stillbirths [11], 23 in Yoremes [17], and 193 in people applying for medical certificates [12]. Thirdly, the research method used in the present study is more stringent for assessing an association that those used in previous studies. In the previous studies, no matching by birthplace and residency was used, whereas in the present study we did.

In the current study, we found that seropositivity to $T$. gondii was associated with a history of hysterectomy. We are not aware of any report about this association. It is unclear why the frequency of infection with $T$. gondii was higher in women with hysterectomy than their age- and gender-matched controls. It is possible that infection of uterus with $T$. gondii may lead to disease of this organ that eventually might lead to hysterectomy. It is known that $T$. gondii infects nearly any nucleated cell, and after infection, spreads to a large variety of organs in the body [18]. Therefore, the uterus may be involved in $T$. gondii infection. In fact, tachyzoite and DNA of 
T. gondii were observed in uterus of mice after experimental vaginal infection [19]. Numerous intra-epithelial tachyzoites of $T$. gondii were found in a Hector's dolphin (Cephalorhynchus hectori) with a marked suppurative metritis [20]. In addition, in experimental infections with $T$. gondii in mice, researchers found accentuated hypertrophy of the endometrium and myometrium [21]. Research to confirm the association between seropositivity to T. gondii and hysterectomy and to determine the role of $T$. gondii infection on uterus pathology in women is needed.

This study was limited by the fact that the association between $T$. gondii infection and a history of surgery was determined in subjects with only some types of surgeries, and few cases in certain surgeries were studied.

\section{Conclusions}

Results of this first age- and gender-matched case-control study about the association between $T$. gondii infection and surgery suggest that having a history of surgery is not an important risk factor for infection with $T$. gondii. However, the link between $T$. gondii infection and a history of hysterectomy found should be further investigated.

\section{Funding Sources}

This study was financially supported by Secretary of Public Education, Mexico (Grant No. DSA/103.5/14/11311).

\section{Authors' Contributions}

CAE designed the study protocol, performed the laboratory analyses, analyzed the data, and wrote the manuscript. ARN, SMCS, MAMH, CAGA, and IBG obtained the blood samples and submitted the questionnaires to obtain the clinical data, and/or performed the data analysis. LFSA and JHT performed the data analysis and wrote the manuscript. SEM and ARPA performed the statistical analysis, and ERS worked in the design of the study protocol.

\section{Conflict of Interest}

The authors declare that there is no conflict of interests.

\section{References}

1. Silva-Gutierrez N, Bahsas Zaky R, Bouchard M, Teran Angel G, Amoroso A, Peterson DL, et al. T-cell profiles elicited by Toxoplasma gondii in acutely/chronically infected humans. Parasite Immunol. 2018:e12532. doi: 10.1111/pim.12532.

2. Hussain MA, Stitt V, Szabo EA, Nelan B. Toxoplasma gondii in the food supply. Pathogens. 2017;6:pii: E21. doi: 10.3390/pathogens6020021.

3. Gagne SS. Toxoplasmosis. Prim Care Update Ob Gyns. 2001;8:122-6.
4. Lee SB, Lee TG. Toxoplasmic encephalitis in patient with acquired immunodeficiency syndrome. Brain Tumor Res Treat. 2017;5:34-6. doi: 10.14791/btrt.2017.5.1.34

5. Wallon M, Peyron F. Congenital Toxoplasmosis: A plea for a neglected disease. Pathogens. 2018;7:pii: E25. doi: 10.3390/pathogens7010025.

6. De Berardinis A, Paludi D, Pennisi L, Vergara A. Toxoplasma gondii, a foodborne pathogen in the swine production chain from a European perspective. Foodborne Pathog Dis. 2017;14:637-48. doi: 10.1089/ fpd.2017.2305.

7. Alvarado-Esquivel C, Sánchez-Anguiano LF, Hernández-Tinoco J, Ramos-Nevarez A, Estrada-Martínez S, Cerrillo-Soto SM, et al. Association between Toxoplasma gondii infection and history of blood transfusion: a casecontrol seroprevalence study. J Int Med Res. 2018;46:1626-33. doi: 10.1177/ 0300060518757928.

8. Webb GJ, Shah H, David MD, Tiew S, Beare N, Hirschfield GM. Postprophylaxis Toxoplasma chorioretinitis following donor-recipient mismatched liver transplantation. Transpl Infect Dis. 2016;18:805-8. doi: 10.1111/ tid.12589.

9. Derouin F, Pelloux H; ESCMID Study Group on Clinical Parasitology. Prevention of toxoplasmosis in transplant patients. Clin Microbiol Infect. 2008; 14:1089-101. doi: 10.1111/j.1469-0691.2008.02091.x.

10. Alvarado-Esquivel C, Alanis-Quiñones OP, Arreola-Valenzuela MA, Rodríguez-Briones A, Piedra-Nevarez LJ, Duran-Morales E, et al. Seroepidemiology of Toxoplasma gondii infection in psychiatric inpatients in a northern Mexican city. BMC Infect Dis. 2006;6:178.

11. Alvarado-Esquivel C, Pacheco-Vega SJ, Salcedo-Jaquez M, SánchezAnguiano LF, Hernández-Tinoco J, Rábago-Sánchez E, et al. Stillbirth history and Toxoplasma gondii infection in women attending public health centers in a northern Mexican city. Eur J Microbiol Immunol (Bp). 2015;5:164-71. doi: 10.1556/1886.2015.00009.

12. Alvarado-Esquivel C, Sánchez-Anguiano LF, Hernández-Tinoco J, Pulido-Montoya RA, Acosta-Rojas G, Estrada-Martínez S, et al. Seroepidemiology of Toxoplasma gondii Infection in People Applying for Medical Certificates. Eur J Microbiol Immunol (Bp). 2016;6:90-8. doi: 10.1556/1886.2016.00001.

13. Alvarado-Esquivel C, Estrada-Martínez S, Pizarro-Villalobos H, ArceQuiñones M, Liesenfeld O, Dubey JP. Seroepidemiology of Toxoplasma gondii infection in general population in a northern Mexican city. J Parasitol. 2011;97:40-3. doi: 10.1645/GE-2612.1.

14. Alvarado-Esquivel C, Salcedo-Jaquez M, Sanchez-Anguiano LF, Hernandez-Tinoco J, Rabago-Sanchez E, Beristain-Garcia I, et al. Association between Toxoplasma gondii exposure and heart disease: A case-control study. $J$ Clin Med Res. 2016;8:402-9. doi: 10.14740/jocmr2525w.

15. Alvarado-Esquivel C, Cruz-Magallanes HM, Esquivel-Cruz R, EstradaMartínez S, Rivas-González M, Liesenfeld O, et al. Seroepidemiology of Toxoplasma gondii infection in human adults from three rural communities in Durango State, Mexico. J Parasitol. 2008;94:811-6. doi: 10.1645/GE-1524.1.

16. Alvarado-Esquivel C, Estrada-Martínez S. Toxoplasma gondii infection and abdominal hernia: evidence of a new association. Parasit Vectors. 2011;4:112. doi: 10.1186/1756-3305-4-112.

17. Alvarado-Esquivel C, Rascón-Careaga A, Hernández-Tinoco J, CorellaMadueño MA, Sánchez-Anguiano LF, Aldana-Madrid ML, et al. Seroprevalence and correlates of Toxoplasma gondii infection in Yoremes (Mayos) in Mexico: a cross-sectional study. BMJ Open. 2016;6:e10218. doi: 10.1136/bmjopen-2015-010218.

18. Harker KS, Ueno N, Lodoen MB. Toxoplasma gondii dissemination: a parasite's journey through the infected host. Parasite Immunol. 2015;37:141-9. doi: 10.1111/pim.12163.

19. Bayat PD, Eslamirad Z, Shojaee S. Toxoplasmosis: experimental vaginal infection in NMRI mice and its effect on uterin, placenta and fetus tissues. Iran Red Crescent Med J. 2013;15:595-9. doi: 10.5812/ircmj.11427.

20. Roe WD, Howe L, Baker EJ, Burrows L, Hunter SA. An atypical genotype of Toxoplasma gondii as a cause of mortality in Hector's dolphins (Cephalorhynchus hectori). Vet Parasitol. 2013;192:67-74. doi: 10.1016/j. vetpar.2012.11.001.

21. Fux B, Ferreira A, Cassali G, Tafuri WL, Vitor RW. Experimental toxoplasmosis in Balb/c mice. Prevention of vertical disease transmission by treatment and reproductive failure in chronic infection. Mem Inst Oswaldo Cruz. 2000;95:121-6. 